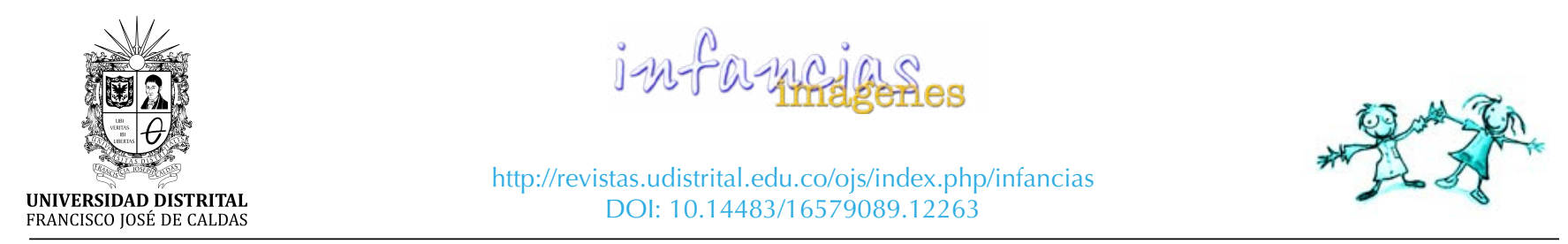

IMÁGENES DE INVESTIGACIÓN

\title{
Escritura creativa en la escuela ${ }^{*}$
}

\author{
Creative writing at school \\ Bárbara Yaneth Guzmán Ayala', Jennifer Paola Bermúdez Cotrina ${ }^{2}$
}

Para citar este artículo: Guzmán, B. Y.; Bermúdez, J. P.

Recibido: 28-junio-2017 / Aprobado: 29-diciembre-2018

(2018). Escritura creativa en la escuela. Infancias Imágenes,

18(1), 80-94

\section{Resumen}

Este artículo tiene como objetivo examinar el devenir de la pedagogía de la escritura en la escuela, para orientarse luego hacia la enseñanza de la escritura de invención como proceso creativo asociado con textos estéticos mediante los cuales cierto perfil de estudiantes se convierte en productor cultural, dejando de lado su papel pasivo. Para esto, nos amparamos en un entendimiento semio-lingüístico del acto escritor (Barthes, 2002; Eco, 1999; Coto, 2006) y, a través del diseño de investigación acción en el aula, detallamos cómo esta práctica explorada facilita el reconocimiento individual de un estudiante de la escuela rural Mancilla, quien presentó su historia de vida a través de la escritura creativa. La detección de este tipo de casos destacados dentro de los resultados de la investigación permite valorar las estrategias auténticas de recreación simbólica de la realidad subjetiva, mostrando los avances logrados con intervenciones que permiten desarrollar procesos escritores en estudiantes.

Palabras clave: escritura creativa, imaginación, creatividad, sensibilidad, visualización.

\begin{abstract}
This paper aims to examine the evolution of writing pedagogy in school, to be faced then towards the invention of writing as a creative process associated with esthetic texts by means of which certain profile students become cultural producers, leaving aside their passive role. For this, we rely on a semi-linguistic understanding of the writing act (Barthes, 2002, Eco, 1999, Coto, 2006) and, through the research design action in the classroom, we detail how this explored practice facilitates the individual recognition of a student at the rural school Mancilla, who presented his life story through creative writing. The detection of this kind of highlighted cases within the results of the research, enable the evaluation of authentic strategies of symbolic recreation of the subjective reality, showing the advances achieved with interventions that allow the development of writing processes in students.
\end{abstract}

Keywords: creative writing, imagination, creativity, sensitivity, visualization.

* Investigación realizada en la sede rural Mancilla de la I.E.M. Manuela Ayala de Gaitán, en el municipio de Facatativá, con un grupo de estudiantes de grado tercero de primaria y que toma en cuenta el caso particular de un estudiante que refleja su historia de vida a través de la escritura creativa de un cuento. Fecha de inicio: febrero de 2016, fecha de finalización: 22 de agosto de 2017. Universidad Distrital Francisco José de Caldas. Programa académico: Maestría en Pedagogía de la Lengua Materna.

1 Administradora de Empresas, Especialista en Docencia Universitaria y Magister en Pedagogía de la Lengua Materna de la Universidad Distrital Francisco José de Caldas. En la actualidad se desempeña como docente de básica primaria. Correo electrónico: barbarayaneth71@gmail.com

2 Licenciada en Pedagogía Infantil y Magister en Pedagogía de la Lengua Materna de la Universidad Distrital Francisco José de Caldas. En la actualidad se desempeña como docente de preescolar. Correo electrónico: jpcotrina41@gmail.com 


\section{Introducción}

Este artículo presenta de manera sucinta la forma como se ha orientado la enseñanza de la escritura en la escuela rural Mancilla, de Facatativá-Colombia. Se hace un recorrido por la forma y los objetivos que la han orientado para desembocar, luego, en la producción de textos de invención a partir de la enseñanza de la escritura creativa que estimula el desarrollo de la imaginación, indispensable para acceder al conocimiento literario. Lo anterior se hace visible con la experiencia escritora de un estudiante de grado tercero de una institución periurbana, quien ejecutó la recreación simbólica de su realidad.

Así las cosas, el objetivo del artículo consiste en evidenciar cómo la enseñanza de la escritura de invención en los entornos escolares contribuye al desarrollo de la sensibilidad literaria a partir de la creatividad. Para ello se plantea el interrogante, ¿qué posibilidades de escrituras de invención facilita la escuela a los estudiantes de básica primaria para conducirlos al dominio mínimo de la expresión escrita? De esta, se desprendería la pregunta: ¿cómo contribuye la escuela a la disponibilidad natural del niño para producir creativamente en diversos códigos que se originan desde el juego en los primeros años de vida? Dicha contribución gira el texto hacia escenarios de aprendizaje de la escritura creativa con adopción de estrategias flexibles, introduciendo la lúdica y la experimentación con las palabras para posibilitarle a los alumnos estimular su imaginación y facilitar el flujo de sus ideas.

A partir de la anterior consideración, se realizó la revisión de investigaciones tendientes a la enseñanza de la escritura creativa en la escuela, analizando sus objetivos, las estrategias adoptadas y los hallazgos que permitan validar la presente investigación en el ámbito de la pedagogía.

De este modo, en primer lugar, es importante reconocer que la enseñanza de la lengua se ha realizado de manera prescriptiva. Lo que se explica en las concepciones de los docentes que la imparten, quienes, en definitiva, deciden qué se debe escribir, cuáles textos son permitidos y cuáles son censurados y qué formas de reconocimiento de la escritura de los estudiantes se establecen en el aula de clase desde los mecanismos de evaluación de uso particular de los docentes, desconociendo la escritura como práctica social y persistiendo en el uso de manuales; en este sentido:

los niños, desde primer grado, son sometidos a programas repetidores y mecánicos, con los cuales se considera pueden aprender a leer y a escribir $y$ cuyo instrumento validador es el manual; desde el manual el niño repite con su maestro listados de sílabas (bla, ble, bli, blo, blu, ma, me, mi, mo, mu), realiza fatigosamente planas de frases estereotipadas ("mi mamá me ama", "el enano come banano"), en donde, como es notable, el sentido poco importa, porque se considera que cuando se logre la perfección en el "hablar bien", como si los niños fuesen mudos al llegar a la escuela, y en el tener una "bonita letra", podrá después el niño acceder a los universos de la significación. (Jurado, 1992, p. 40)

Como lo refleja Jurado (1992), es necesario contribuir al desarrollo de la subjetividad a partir de la enseñanza de la escritura para que ésta tome en cuenta la dimensión cotidiana del estudiante y le permita activar la sensibilidad en cada propuesta escrita.

Lo anterior, se posibilita en escenarios escolares que permitan considerar las múltiples posibilidades que tiene el juego con el lenguaje en la producción de textos, mediante la subversión de lo tradicional y amparado en una práctica pedagógica que atribuye significado a la experiencia.

En segundo lugar, se aborda la enseñanza de la escritura creativa y se destaca su contribución con el desarrollo de habilidades para la producción literaria, estableciéndose como mecanismo desde el cual niños y niñas construyen y deconstruyen el mundo, perciben su realidad de forma diferente, se convierten en narradores de sus vivencias, en productores culturales, se responsabilizan de las expectativas que tienen frente al conocimiento y se acercan a la escritura en forma natural mediante el desarrollo de la imaginación y la creatividad, como lo propone Sergio Frugoni (2006) en su libro Imaginación y Escritura.

En tercer lugar, se presenta, como ejemplo local, el caso de un estudiante que interpreta su realidad desde la sensibilidad, recreándola en un escrito de 
aproximación al entorno literario. Este fue un acto logrado mediante la flexibilización de la enseñanza de la escritura en el aula que involucra el contexto del estudiante, obteniendo respuestas satisfactorias en sus historias de vida emanadas de la cultura y los modos de ser y habitar en esta. Asimismo, se hace alusión al lugar; el sector rural, las vivencias de la población que lo habita, además de sus costumbres y la construcción de sujetos a partir de estas, aspecto que se evidencia en el escrito del estudiante.

El artículo se ampara en una perspectiva semio-discursiva para poder valorar el proceso de la escritura creativa.

\section{Lugares comunes de la escritura en la escuela}

Reflexionando acerca del papel de la escritura en la escuela, fácilmente se evidencia cómo esta práctica es común en todas las áreas del conocimiento. Se escribe para registrar conceptos producidos por otros, diligenciar formatos, responder cuestionarios de evaluación, comunicarse entre pares; se escriben cartas, anotaciones personales, se escribe en el pupitre, en las paredes y hasta en las puertas de los baños toda clase de información clandestina o pública. Se llenan cuadernos y se comienzan otros y la escritura no se detiene, circula en diferentes medios y es una de las formas habituales de evaluación y de sanción en la escuela.

Pese a ello, la escuela no brinda espacios para el ejercicio de la reinvención de la escritura a través de la intertextualidad que comunique, por intermedio de la imaginación, vivencias, mundos ideados, realidades diversas inventadas y descabelladas, sentimientos y emociones. Esto ocurre pues, aparte del cuaderno repleto de conceptos y reproducciones de otros textos, la enseñanza de la escritura en la escuela rural en el municipio de Facatativá, de acuerdo con la lectura del contexto evidenciada mediante instrumentos de recolección de información, desconoce los lugares que relacionen al estudiante con su mundo interior a partir del juego con las palabras como desencadenante de producciones emancipadoras en el aula de clase.

Por lo anteriormente expuesto, se retarda el desarrollo de habilidades escriturales en los educandos, lo que es reflejo de las dificultades que enfrentan cuando deben producir escritos autónomos o responder pruebas de escritura en evaluaciones externas, y no cuentan con la competencia para el efecto. Como lo devela el informe de las Pruebas Saber 2016 para la entidad territorial (Facatativá) que, en referencia al desarrollo de la competencia escritora, evidencia que el $35 \%$ de los estudiantes no contestó correctamente las preguntas relacionadas con la escritura, lo que refleja el bajo desarrollo de habilidades escritas de los estudiantes de grado tercero de primaria en la entidad territorial.

Del mismo modo, el informe por colegios muestra que el $47 \%$ de los estudiantes de grado tercero no contestó correctamente las preguntas correspondientes a producciones escritas en la prueba de lenguaje, lo que refleja su bajo nivel de competencia escritora.

De este modo, es notorio que a pesar de los esfuerzos que realizan cada día los profesores por enseñar la escritura, los métodos no están siendo eficaces, pues no se exteriorizan los aprendizajes en las pruebas de medición externas. En tal sentido, la profesora Amparo Tusón afirma que:

Uno de los principales objetivos de la escuela es enseñar a escribir a los estudiantes. Así pues, si los estudiantes fracasan en sus escritos, ello evidencia, también, que los profesores fracasamos en la manera como les enseñamos y les corregimos. Si analizamos las correcciones que los profesores hacemos en los textos de nuestros estudiantes, podremos observar que esas correcciones corresponden a categorías muy diferentes (ortografía, selección morfosintáctica y léxica, organización textual, "contenidos", etc.) que, la mayoría de las veces, ni los profesores hacemos explícitas ni los estudiantes comprenden. (1991, p. 2)

La escritura reducida a la construcción de oraciones correctas y uso adecuado de signos de puntuación, centrada en la toma de dictado, el desarrollo de cuestionarios interminables y mediada por el texto guía ha encarnado las prácticas escolares de los docentes por decenios. También, se ha instalado en las mallas curriculares en forma de contenidos fragmentados, lo cual genera producciones dirigidas a un único destinatario (el maestro) quien imparte, pero no orienta la enseñanza de la 
escritura como un proceso; concepción que requiere de acompañamiento y reflexión sobre la marcha.

Lo anterior deriva de las representaciones mentales que subyacen en los docentes sobre la enseñanza de la escritura, de los modelos de enseñanza centrados en los contenidos y de las orientaciones pedagógicas contenidas en los libros de texto de las empresas editoriales (los cuales se constituyen en el principal insumo utilizado por los docentes para la enseñanza de la lectura y la escritura en la escuela).

Es por ello que el uso de los textos guía se acentúa en la escuela rural; ante la ausencia de "otras" herramientas que permitan acercar al estudiantado a la escritura en tanto práctica escolar. Es decir, el desconocimiento que tienen los docentes de básica primaria (determinado mediante la LEC) acerca de la literatura y sus múltiples posibilidades para la enseñanza de la lengua y las tecnologías de la comunicación, para el efecto, la conectividad que representa una dificultad en las zonas rurales del municipio.

Derivado de lo anterior, y en el reconocimiento de la escritura como actividad personal en relación con la cultura y los saberes de los estudiantes (amén de la representación que construyen de los eventos y los lugares), se requiere de procesos de acompañamiento que los conduzcan al encuentro de la significación a partir del desarrollo de la escritura personal, capaz de imbricar la realidad circundante con múltiples interpretaciones.

En esta lógica, el docente se convierte en promotor de vínculos entre la palabra y el juego. Es este quien da un lugar preponderante a la invención y desarticulación del lenguaje mediado por consignas de producción y amparado en la lectura (en su papel de intermediaria entre la consigna y la escritura), saliendo de lo habitual para ceder espacio a las construcciones que realiza la mente con el lenguaje y desde las cuales se da inicio a la palabra esencial: la escritura autónoma en los estudiantes. A propósito de lo cual, Carol Contreras y Cristina Giraldo, a la luz de los postulados de Maurice Blanchot, manifiestan que:

Por un lado, la palabra bruta, que refiere al mundo y representa las cosas, lo que podríamos Ilamar lenguaje ordinario, genera (y es generado por) pensamientos lineales, causales, lógicos y formales. Por otro lado, palabra esencial, la que habla desde sí misma inventando y presentando nuevos mundos y diferentes formas de comprender la realidad, crea y es concebida por pensamientos divergentes innovadores, trasgresores y asociativos que trastocan la manera en que experimentamos el mundo. Así, al propiciar y ejercitar un trato distinto con el lenguaje, al conocer, asociar y contraponer, en últimas jugar con las palabras, es como se podría desarrollar un pensar creativo. (2011, p. 77)

Atendiendo a la cita referenciada de las autoras Contreras y Giraldo, la alusión a la palabra bruta se puede asociar con la enseñanza obligatoria de la lengua, dentro de los modelos didácticos de uso habitual en la escuela ya que, en particular:

[...] el conocimiento escolar es producto de los desarrollos disciplinarios: retórica, gramática o lingüística, historia o teoría literaria y de la acumulación de tradiciones de enseñanza, así mismo, del impacto que la propia producción cultural contemporánea tiene en los contenidos de enseñanza. (Bombini, 2006, p. 19)

Frente a este panorama, el currículo de la escuela tardará un tiempo en ser apropiado por los docentes, quienes, a partir de la reflexión constante, la revisión de sus concepciones y su posterior movilización lograrán promover en los estudiantes una actitud creativa y estética desde la enseñanza del lenguaje y la literatura, que se reflejará así mismo en la escritura.

Del mismo modo, el docente debe alentar en sus estudiantes el espíritu de negociación, de trabajo en equipo y de recreación de significado, así como alimentar su curiosidad del para lo cual la mediación con la literatura le será de ayuda. En tal sentido, se propone que la enseñanza del lenguaje se dirija:

Hacia la construcción de la significación, a través de los múltiples códigos y formas de simbolizar, experiencia que tiene lugar a través de procesos históricos, culturales y sociales en medio de los cuales se construyen los sujetos en y desde el lenguaje. 
(Ministerio de Educación Nacional de la República de Colombia, 1998, p. 46)

A partir de la propuesta emanada de los Lineamientos de Lenguaje se puede repensar estrategias para la enseñanza de la lengua, con la introducción de la literatura y la escritura en el aula "[...] y que promuevan trasformaciones en los modos de pensar el conocimiento escolar y el modo de trabajar en el aula" (Bombini, 2006, p. 33). Así lo propone también Sergio Frugoni, citando a Maité Alvarado, quien, en referencia a la enseñanza de la escritura con articulación de la literatura, señala que:

Una de las características más significativas de los escritores expertos es la de poseer una habilidad adquirida de construir una representación retórica de la tarea, que toma en cuenta las restricciones genéricas y discursivas del texto que tienen que producir. Es en función de esas limitaciones: —el género elegido, la situación de comunicación, los posibles destinatarios, los objetivos que se pretenden-que los escritores expertos adecúan las características de su escrito. Esta habilidad, les permite construir enunciadores diversos y adecuarse a diversos auditorios, así como reformular sus textos y producir versiones distintas en función de la situación. (Citado en Frugoni, 2002, p. 6)

De esta manera, es más posible propender por el desarrollo de un estilo literario propio, en concordancia con la enseñanza que, desde la pedagogía de la literatura, proponen los Estándares Básicos de Competencias en Lenguaje cuando señalan que:

También se debe estimular la capacidad productiva de los estudiantes, es decir, estimular y propiciar la escritura con intención literaria: cuentos, sociodramas, poemas, ensayos, etc.; de tal forma que puedan expresar sus formas particulares de sentir, ver y recrear el mundo, a la vez que desarrollen su producción escrita, teniendo en cuenta que el texto literario aporta al mejoramiento de las capacidades expresivas, imaginativas y cognitivas de los estudiantes. (EBCL, 2006, p. 26)

Desde los postulados expuestos, se propone la enseñanza de la escritura creativa al estudiante en el aula, para que pueda integrar las dos modalidades de pensamiento: el paradigmático-lógico y el narrativo. Lo anterior, parafraseando a Bruner (1998), posibilita la diversidad en el pensamiento, afecta la individualidad hacia el desarrollo de la imaginación y el pensamiento divergente, trasforma sus formas de concebir el mundo y desarrolla en el estudiante el espíritu investigativo, la capacidad de sorprenderse y de renovarse ante la vida; aún más, desarrolla la posibilidad de generar una empatía que le permita reconocerse y reconocer al otro en su contexto y en su singularidad.

Es así como algunos registros hallados en relación con la escritura de invención dan cuenta de su contribución en el fortalecimiento de las relaciones interpersonales en el aula de clase, de la ampliación de la capacidad creadora en los estudiantes y del desarrollo de procesos escritores, demostrando que la enseñanza de la escritura creativa cuando se distancia de la enseñanza tradicional favorece el desarrollo de competencias escritas y contribuye al despertar de la sensibilidad en los estudiantes.

Aunque son pocas las investigaciones acerca de la enseñanza de la escritura creativa en la escuela, se han encontrado registros correspondientes a los últimos 14 años, entre los cuales, destaca el de Alonso y Aguirre (2004), quienes realizaron una experiencia pedagógica en la modalidad de taller con niños de quinto grado de primaria, para favorecer el desarrollo de la imaginación verbal, con mediación de lecturas literarias amparadas en los postulados de Beuchat y Lira (1995), demostrando que el contacto de los estudiantes con la literatura, además de favorecer el conocimiento de formas lingüísticas, posibilita la capacidad de imaginar, sentir y comprender la realidad desde perspectivas diversas, propuesta que finaliza con la presentación de creaciones inéditas y con calidad literaria de los estudiantes y que reflejan un trabajo mediado y ejecutado con flexibilidad.

En la misma perspectiva, destacan investigaciones como la de Álvarez (2009), encaminada a propiciar la escritura a partir de la implementación de las técnicas de Gianni Rodari (1983). Con esta, y con la inserción de consignas, azuza el ejercicio de una escritura lúdica, contribuyendo al desplazamiento en el uso instrumental del lenguaje en la 
escuela, para dar inicio a la producción literaria en la cual la lectura profunda gana importancia en la producción escrita; la que solo se consigue conjugando acciones y combinando campos del mundo literario y social.

Así mismo, López, (2004) convierte el aula de clase en un café literario con presencia de lectores externos e involucramiento de talleres de escrituras a partir de la lectura con niños tendientes a la elaboración de minitextos. Con ello, despoja a la enseñanza de la literatura de su ámbito canónico y trabaja a favor de la experiencia de los estudiantes. Dicha investigación culmina con el desarrollo de estrategias de lectura y escritura por parte del alumnado que redundaron en el mejoramiento de su competencia comunicativa.

Hallazgos similares se encontraron en las investigaciones de Angulo (2015), con su propuesta de creación literaria en la biblioteca a través del blog, que trasladó la práctica desde la escuela a la biblioteca con implementación de talleres encaminados a fortalecer la escritura de invención. En el mismo sentido, Correa (2015) puso en marcha su investigación en la producción de textos a través del grafiti, introduciendo la metacognición como estrategia para la organización y presentación de los textos escritos a partir de la planeación, corrección y edición con promoción de la crítica colectiva en la producción de mejores escrituras.

De manera similar, Rodríguez (2015) propone el fortalecimiento de la escritura desde la producción de relatos de experiencia, permitiendo que se involucren en el proceso conocimientos, experiencias y emociones a partir de los talleres pedagógicos. Esto, mediante la adopción y profundización de un género específico que instó a la integración, por parte de los docentes, de nuevas formas de escritura en la escuela y en donde la significación en torno a las vivencias reales cobra sentido y refleja en las nuevas producciones, la importancia de producir la historia desde las múltiples formas en que los estudiantes conciben el mundo.

Entre tanto, Martínez (2014) reconoce a la narrativa como posibilitadora de prácticas de alfabetismo emergentes y las introduce como formadoras de conceptos y aprendizaje de la lengua materna a partir del reconocimiento de la realidad expresa en la cotidianidad. En sus planteamientos de que las narrativas de los niños permiten su involucramiento en el alfabetismo de forma coherente y significativa, la autora propende por el registro de narrativas en niños surgidas de la interacción para la enseñanza de la lengua materna de una manera novedosa y funcional. De manera semejante, Silva (2015) intenta fortalecer la argumentación mediante la manipulación formal y funcional del microcuento desde una perspectiva sociocrítica con intervención de la metacognición como parte del proceso de desarrollo de la producción escrita, investigación que introduce el desarrollo de la crítica desde la escritura.

Las anteriores investigaciones se sustentan en un aprendizaje de la escritura desde una concepción que atiende a la valoración del contexto de los estudiantes como posibilitador de producciones más reales.

De esta suerte, los hallazgos reflejan que vincular prácticas de escritura en el aula que involucren la reflexión y que motiven al estudiantado a escribir a partir de actividades que estimulen su imaginación y creatividad permite que esta sea asumida como experiencia íntima, estética emanada de una relación cercana con la literatura que facilita el acceso a nuevos conocimientos, a la constitución de equipos de trabajo en el aula, desarrolla la empatía y motiva al ejercicio de una ciudadanía responsable.

\section{Sobre el arte de escribir: "el taller de escrituras creativas"}

Para dar inicio a la segunda parte, nos valdremos de una frase de la escritora Jacqueline Held en alusión a la pedagogía: "[...] para una enseñanza creadora de mitos, una literatura que no se limite sólo al saber, sino que desarrolle la imaginación poética y la creatividad del niño" (1981, p. 11).

Sobre el arte de escribir de forma más eficiente valdría la pena formular cuestionamientos en relación con la enseñanza del lenguaje, concebido este como un conjunto de estructuras y normativas invariables que le impiden al estudiante incurrir en trasgresiones, con lo cual se suprime el desarrollo de su imaginación y su creatividad; acción que, con el tiempo, despoja al niño del lenguaje creador, producto natural de su pensamiento animista. 
En este sentido, se hace necesaria la búsqueda de respuestas acerca de las posibilidades de escrituras autónomas que otorga la escuela a los estudiantes para conducirlos al dominio mínimo de la expresión escrita, y de cómo contribuye la escuela a la disponibilidad del niño para crear palabras que dan origen a la fantasía en los primeros años de vida. La formulación de dichos cuestionamientos se sustenta en la afirmación de que:

Las historias estrictamente realistas van contra las experiencias internas del niño; él les prestará atención y quizá pueda obtener algo de ellas, pero nunca extraerá ningún significado personal que trascienda su contenido evidente. Dichas historias informan sin enriquecer, cosa que, por desgracia, vale también para gran parte de lo que se aprende en la escuela [...]

Las historias realistas resultan, por sí solas, algo completamente inútil. Sin embargo, cuando se combinan con una orientación amplia y psicológicamente correcta referida a los cuentos, el niño recibe información que se dirige a las dos partes de su personalidad en desarrollo: la racional y la emocional. (Bettelheim, 2001, pp. 61 y 62).

A partir de lo anterior, la labor del docente está Ilamada a reinventarse frente a sus prácticas áulicas, despojándose de los imaginarios construidos socialmente; en donde su tarea consiste en el desarrollo de hábitos repetitivos que homogenizan el saber y ocultan la riqueza que se esconde tras el juego verbal del misterio que engloban las palabras cuando se inventan por el niño para resignificar la realidad. En este sentido, se rescatan las múltiples posibilidades que, frente al aprendizaje de la lengua, constituye el taller de escrituras creativas una forma de aprender jugando a desarticular, desarmar, dislocar y, en un sentido más estricto, fantasear con la palabra; en síntesis: "[...] a recrear los significados más no a la transmisión de conocimientos" (Bruner, 1998, p. 4).

Pero, ¿qué es exactamente un taller de escrituras creativas? Ante todo, puede concebirse como "[...] un operador múltiple de textos", ya que "[...] operar textos implica recorrer casi todas las preposiciones (operar bajo texto; con, contra texto; de, desde, en texto; hacia y para texto; por texto...) y algunos verbos monstruosos (haber texto, hacer texto, ser texto" (Alvarado, 1981, p. 9).

Aclarando la forma con que la autora precisó el término, se entiende el taller como una apuesta pedagógico-didáctica que permite tomar como protagonista un texto y abordarlo desde su origen; pero también desde su procedencia, destino, dirección, lugar, medio, punto de partida, motivo, etc. Promoviendo así la escritura de textos estéticos y devolviendo al niño su derecho a la fantasía y al disfrute de la imaginación, justo aquello que en palabras de Rodari (1983, p. 25), trae consigo el regreso a la risa en la educación de la mente.

En el taller de escrituras creativas un grupo de niños se reúne bajo la supervisión de un regulador para practicar la escritura, convirtiendo el aula en un lugar para compartir textos individuales o colectivos, creando y realizando lecturas de lo construido. Pero, también, corrigiendo sobre la marcha, comentando los nuevos escritos y preparando al estudiante como escritor potencial. El texto literario cobra importancia en la medida en que contribuye a la extensión de los conocimientos porque facilita la comprensión e interpretación en la producción de nuevas escrituras creativas, favoreciendo el desarrollo de metáforas imaginativas y creativas que, en palabras de Lakoff y Johnson, [...] "pueden proporcionarnos una nueva comprensión de nuestra experiencia. Pueden dar nuevo significado a nuestras actividades pasadas, así como a las actividades cotidianas, y a lo que sabemos y creemos" (2009, p. 181).

Para sintetizar, el taller de escrituras creativas le devuelve al niño el gusto por las palabras "salvajes" que, en parafraseo de Held, consiste en tomar las palabras civilizadas y retomarlas para hacerlas decir otra cosa; como en los juegos de manos que constan de una serie de repeticiones cantadas que atienden a un lenguaje disparatado, desinteresado, no utilitario, que los niños al cantar trasforman y prolongan con sonidos graves y agudos en un juego de creación y recreación de la palabra con absoluta libertad (1985, p. 155). Así las cosas, el taller de escrituras creativas se constituye en un espacio abierto en el aula de clase, en donde se facilite la interacción de los estudiantes entre sus conocimientos y sus vivencias, con el fin de facilitar la 
lectura compartida y la discusión grupal que implica al mejoramiento de los textos producidos y les permite a los participantes aprender a mirar, nombrar y sentir el mundo de una manera diferente a la tradicional.

Y para lograr este tipo de desarrollos en la clase de lengua mediante la intervención con talleres de escrituras creativas, es importante la mediación de las consignas de invención ${ }^{3}$ que, según Frugoni (2006), son frases que ayudan a estimular la imaginación en momentos precisos, capaces de evocar mundos ficcionales en donde la aventura se convierte en el ingrediente principal, un trabajo parecido a un juego, pero capaz de incitar a la reflexión acerca de la recreación de la realidad. Igualmente, reconocen los conocimientos culturales y académicos con los que cuentan los estudiantes y que se ponen en juego a través de la producción de textos estéticos con los que se puede enseñar literatura en el aula; de este modo, los estudiantes, evolucionan; pasan de consumidores a pro-sumidores de sus propias creaciones.

\section{Metodología}

Se adoptó el diseño de investigación-acción, enmarcada en el enfoque cualitativo que permite determinar un problema que surge de la práctica educativa y tiene dentro de sus características sobresalientes que los resultados sean aplicados a una realidad concreta, aportando a la trasformación de alguna actividad pertinente. Pues, dentro del proceso de investigación se plantea el cambio social, mientras que las técnicas de recolección de datos ofrecen variopintas posibilidades que le permiten al investigador adoptar diversas estrategias para la recolección de información.

Ya que el propósito que se plantea desde la investigación acción es la resolución de problemas habituales e inmediatos, se ha tomado este diseño como punto de partida para ejecutar la investigación con el fin de transformar la realidad que se evidencia en el aula de clase con respecto a la

3 Maité Alvarado (1981) define la consigna como una fórmula breve que incita a la producción de un texto que, en ocasiones linda con el juego, mientras que en otras se convierte en una fórmula matemática, pero en cualquier situación, siempre, la consigna tiene algo de valla y algo de trampolín, algo de punto de partida y algo de punto de llegada. enseñanza de la escritura creativa. Esta misma dará en la medida en que se produzca en torno a la problemática asociada a las prácticas docentes un proceso de reflexión y toma de conciencia que admita, de manera natural, el cambio para la superación de la dificultad.

Asimismo, la investigación-acción permite acceder al conocimiento desde la práctica, luego, la transforma, mejorando la realidad. Pero, para lo cual es indispensable la cooperación de la colectividad, ya que es la comunidad la que reconoce las dificultades y ayuda en la solución, con la intención de modificar el contexto para su beneficio. Dicho en palabras de Eliot,

[...] el objetivo fundamental de la investigación acción consiste en mejorar la práctica en vez de generar conocimiento. La producción y utilización del conocimiento se subordina a este objetivo fundamental y está condicionado por él. Fortalecer las condiciones de vida de la comunidad y sus participantes para potenciar las diversas dimensiones sociales, es decir, lograr proponer situaciones que favorezcan las relaciones de convivencia y las interacciones con el conocimiento en la cotidianidad escolar. (1993, p. 67)

La investigación se llevó a cabo en la sede rural Mancilla adscrita a la I.E.M. Manuela Ayala de Gaitán en Facatativá, con una población de 20 estudiantes de grado tercero quienes, bajo la modalidad de taller como enfoque pedagógico, realizaron nueve ejercicios de escritura con el fin de cualificar la producción de textos estéticos. Para ello, se propuso la integración de diversas figuras retóricas que enmarcaran como estéticos a sus escritos; durante el tiempo en que se llevó a cabo la intervención los estudiantes tuvieron ocasión de participar en un concurso de narrativa organizado por el Colegio Colombia Hoy, ubicado en la vía Facatativá-Rosal y dirigido a estudiantes de Sabana Occidente.

Durante la fase de intervención los ejercicios de producción escrita en el aula siempre estuvieron antecedidos por la lectura literaria que actúo como molde retórico para ayudar a los estudiantes, inicialmente de la mímesis, para luego pasar a la creación en la producción de textos semejantes a los compartidos en clase y escritos por autores 
reconocidos en el mundo de las letras. Así es como antes de enfrentarse a la escritura de un relato relacionado con su historia personal, los estudiantes en el aula de clase bajo la supervisión de la docente de lenguaje, compartieron el libro ¡Pero yo soy un oso!, del autor Frank Tashlin, mediante la técnica de lectura para los demás. Esta se trata de una narración cargada de repeticiones y con uso abundante de figuras retóricas en la que se resalta el derecho a ser diferentes mediante una historia que cuenta la vida personal de un oso a quien nadie le cree y lo confunden con un hombre tonto, sin afeitar y con un abrigo de pieles.

Las consignas que alentaron la producción de narrativas relacionadas con las vivencias de los estudiantes en sus contextos familiares se convirtieron en un pretexto. Esto es, en palabras de Alvarado (1981), en un texto capaz de producir otros, o de producir el espacio donde se producen otros. En tal sentido, la consigna propuso sencillamente escribir un relato de vida, el trampolín (lo que alienta al estudiante a escribir) consistía en narrar a manera de cuento situaciones personales habituales en la vida extracurricular de los estudiantes, la valla (lo que impone restricciones) era el uso de figuras retóricas como repeticiones, exageraciones y comparaciones estudiadas y reconocidas en clase a partir de la lectura literaria.

Así, los estudiantes construyeron sus narrativas, sin la necesidad de inventar historias fantásticas con personajes ficticios, sino arriesgándose a contar sus propias vivencias de las cuales ellos mismos se convertían en los personajes centrales. Para dicho ejercicio de escritura, la mediación docente fue fundamental pues facilitó la interacción entre pares para que en el intercambio oral se contaran sus historias personales y luego se atrevieran a escribirlas; siempre bajo la guía del interlocutor, quien ayudó a recuperar los eventos que el estudiante escritor olvidaba durante el cambio de canales.

Del mismo modo, la docente mediadora posibilitó al estudiantado reparar en su propio entorno mediante la ejemplificación de sucesos habituales a los niños en ámbitos rurales, alentó la observación, el hallazgo de detalles incitándolos a escudriñarlo todo, con la finalidad de alimentar la imaginación. Lo anterior, siguiendo a Vygotsky en su postulado de que "Alimentar la imaginación del niño le permitirá creer que sí es capaz de combinar y de reelaborar creativamente los datos de la experiencia, inventando nuevas situaciones, nuevos desarrollos y nuevas soluciones narrativas" (2004, p. 17). De suerte que, la docente mediadora debió dotarse de una gran flexibilidad académica, otorgando tiempo para la construcción y realizando una revisión personalizada con la finalidad de exhortar a los estudiantes con el comentario y la discusión colectiva a mejorar los escritos para su publicación.

Ahora bien, con la certeza de que en la literatura se encuentra el camino que alienta la imaginación del lector (Bettelheim, 2001), y más cuando este aún es un niño, porque le permite interrogarse desde los aspectos más insignificantes, hallando la solución a sus problemas trascendentales, ayudándole a resolver su necesidad más urgente y difícil que es la de encontrar un significado a su vida, la docente de lengua materna facilitó ese acercamiento del niño con el texto literario para contribuir a estimular su imaginación y excitar su curiosidad.

De este modo, como lo expresa Fajardo (2017), citando a Colasanti (2004), en última instancia la literatura no es otra cosa que un largo e interminable discurso sobre la vida, un artificio en el que por media de la narrativa los seres humanos elaboran sus pasiones, sus angustias, sus miedos y se acercan al gran enigma del ser. Leyendo no solo aprendemos a poner en palabras nuestros propios pensamientos. También obedeciendo a representaciones simbólicas, aprendemos de la vida (Colasanti, 2004, como se cita en Fajardo, 2017).

Así, la docente de lengua materna se amparó en la lectura literaria del relato ¡Pero yo soy un oso!, que además de actuar como molde retórico para la escritura de los estudiantes fue un ejemplo del manejo de longitud y extensión, permitiendo a la docente analizar con el grupo las descripciones de dicha historia, que solo se centraban en lo esencial. Así mismo, contribuyó en la construcción de inicios inusitados, desplazando hacia otras posibilidades el "había una vez" propio del comienzo de los cuentos clásicos de la literatura y recurrente en las historias escritas por niños.

En búsqueda de la originalidad en el relato, la propuesta se centró en convertir eventos cotidianos 
en narrativas que dirigieran el pensamiento hacia actividades conocidas por los estudiantes $y$, por lo mismo, originales, pues a nadie le suceden las historias personales de los demás; está fue una forma de lograr la diversidad en todas las historias. A su vez, la lectura literaria también alentó la construcción de finales diferentes. No necesariamente se debía buscar un final feliz, bastaba con dejar una posibilidad abierta al lector de imaginar su propio final.

Frente al enfoque literario desde el cual se llevó a cabo la investigación, se alude a una concepción estética del texto literario, ya que como lo plantean los Lineamientos Curriculares de Lengua Castellana, la literatura se abordó en el aula a partir del juego como:

[...] invertir el orden de las partes de un poema que le ha "gustado" al estudiante, continuar y "completar" la historia que se narra en un cuento, cambiar los nombres y los roles de los personajes, escribir un texto ficticio según se considere lo más emocionante del texto leído, enviarle una carta al personaje que más le ha llamado la atención, o al autor, etcétera. Se trata de lo que podríamos Ilamar recreación del texto, en aras de hacer aflorar el efecto estético; en estos casos hallamos un énfasis en la dimensión estética. (Ministerio de Educación Nacional de la República de Colombia, 2008, p. 52)

Así, la enseñanza de la escritura creativa en la escuela rural ayudó en los estudiantes la construcción de textos estéticos, mediante un trabajo intermediado en el que la docente de lengua, en su función de mediadora, realizó una revisión personalizada a los textos de los estudiantes para determinar avances y dificultades en la construcción de textos estéticos, facilitó el trabajo en equipo, favoreció el arbitraje entre los estudiantes rezagados y los más adelantados para el logro del objetivo, alentó la puesta en común de los relatos de cada uno de los estudiantes mediante la lectura en voz alta, exhortó al comentario para el mejoramiento de los textos sobre la marcha y otorgó los tiempos necesarios para estimular procesos de reescritura y adecuación de los textos orales al registro escrito; con las implicaciones que esto acarrea, entre estas, el uso de signos de interrogación, admiración, comillas, guiones y demás aspectos que revisaba de manera individual y que explicaba para la colectividad mediante ejemplos extraídos de los textos literarios.

La escritura creativa desde y para la vida: "entre cerdos y más cerdos"

Para finalizar, se presenta una experiencia de escritura creativa en el aula de clase, surgida en el proceso de intervención a un grupo de estudiantes de grado tercero perteneciente a la escuela rural Mancilla en el municipio de Facatativá (Cundinamarca). Para ello, nos amparamos en la tesis que afirma que:

La invención individual quizá sea la fuente más recurrida y la más rica para la creación. Se extiende desde la experiencia cotidiana hasta lo aprendido en los testimonios ajenos, desde la imagen captada en un instante por cualquiera de nuestros sentidos hasta la historia relatada por un amigo o leída en un libro. (Peña, 2010, p. 42)

Y es la experiencia cotidiana la que se relata a continuación, a través de la escritura del estudiante a quien Ilamaremos Caleb para proteger su identidad, quien a partir de una consigna que solicitaba simplemente narrar a manera de cuento un relato de vida, introduciendo en la escritura algunas figuras retóricas, ingresó al complejo ámbito de pensamiento creativo, desarrollando espacios en la imaginación que le permitieron organizar sus ideas para volcarlas en la hoja en blanco. Todo esto, haciendo eco a los postulados de Barthes (2002) cuando establece la relación de la escritura estética con el cuerpo en la siguiente declaración: "[...] solamente conozco de mi escritura lo que conozco de mi cuerpo, una cenestesia, la experiencia de una presión, de una pulsión, de un deslizamiento, de un ritmo, una producción y no un producto, un goce y no una inteligibilidad" (2002, p. 123).

Así, realizando un análisis estructural del relato del estudiante, esa pulsión que menciona el autor es la que anima a Caleb a dar cauce a sus experiencias vitales a través de una narración en la que da cuenta de los oficios a los que debió enfrentarse una noche ante la ausencia del padre, y que lo 
Ilevaron a asumir responsabilidades para las cuales no tenía la edad y la preparación suficientes, venciendo las adversidades, entre estas el miedo a la pérdida del amparo y la soledad, surgidos del extravío temporal de la figura paterna refundida entre sus deberes y sus responsabilidades trascendentales, como se evidencia en el siguiente fragmento:

Mi familia y yo vivíamos en una finca que tenía una marranera, la finca no era de nosotros, pero teníamos que cuidar a los cerdos y responder por ellos. Un día falleció un familiar de mi papá y él se tuvo que ir muy lejos, entonces ya no le pudo seguir ayudando a mi mamá a cuidar tantos cerdos y, por esos días se murió un marrano y mi mamá, mis hermanos y yo tuvimos que arreglarlo y echarlo al congelador de cerdos, porque el patrón tenía en la casa un congelador grande para guardar a los cerdos cuando se sacrificaban o cuando se morían del susto y después él venía a recogerlos y se los llevaba, yo no sé para donde, pero se los llevaba.

A los cerdos que quedaban vivos y que eran cuatrocientos, mi mamá y yo les dábamos de comer, cuando se murió el marrano, llegó don Dionisio con cincuenta marranos más. Esa noche llovía muy fuerte y don Dionisio se fue para su casa en su carro a descansar y dejó los cerdos en el camión, pero como nosotros teníamos que cuidar los marranos, tuvimos que comenzar a bajarlos del camión, untarlos de creolina para que no se pelearan y se mordieran y cargarlos hasta las marraneras; cargamos cuarenta y cinco cerdos y diez marranas. Tuvimos que arreglar las marraneras, ponerle el doble piso y contarlos y recontarlos para no equivocarnos. Estábamos empapados y era muy noche, yo tenía que ir a la escuela al día siguiente, mi papá se había ido y estábamos solos.

A través de la narrativa, el estudiante va revelando la ausencia reflejando en su escritura con cierto grado de aflicción, su transformación en la imagen de autoridad y de control que salvaguarda a la familia resolviendo con coraje las dificultades cotidianas, como lo devela en el siguiente fragmento:

Esa noche se murieron cinco cerdos más, eso siempre pasa cuando llegan los cerdos a la finca, se asustan mucho y se mueren. Mi mamá y yo tuvimos que comenzar a pelar y arreglar los cerdos porque don Dionisio le paga para eso. Pero había un problema, los cerdos arreglados ya no cabían en el congelador grande, entonces tocó cerrar la puerta y dejarlos sobre el congelador envueltos en lonas de las mismas en que viene el concentrado, esperando que no se dañaran. Esa misma noche, muy tarde, mi mamá llamó al patrón para contarle y que él viniera por los cerdos arreglados; a las diez de la noche el patrón llegó y se los llevó...

Esta historia da cuenta del desarrollo de destrezas expresivas con cierto grado de subversión en el orden establecido de las palabras y en la conformación del texto, dando relieve a nuevos modos de entendimiento de la experiencia propia, lo cual le surge de manera natural. Así, Caleb va integrando el uso de la redundancia, tan habitual en los textos estéticos, cuando bautiza su cuento con la frase: "entre cerdos y más cerdos". A partir del título, Caleb le imbuye fuerza a su escrito, reitera el significado afectando el significante, enfatizando en la circunstancia que atraviesa en el momento en que escribe la historia, de la misma forma en que lo señala Eco (1999, p. 139), para así ir construyéndose un estilo propio que le permite el desvío de la forma lingüística de manera funcional expresado en la desviación de las palabras para rescatarlas de su función instrumental a través de estrategias como la hipérbole (450 cerdos para ubicar en cobertizos), y la forma connotativa de usar la expresión "Se murió del susto".

Todo en el relato de Caleb es funcional para un análisis contextual: la mención reiterada de los cerdos, la ausencia del padre, la lluvia sin pausa, el cansancio del niño en la escuela. Esto aporta a los indicios que remiten al significado constitutivo de la historia, con significantes diferentes en donde lo connotado desborda lo denotado y permite establecer la incidencia del contexto en la formación del estudiante, en concordancia con Barthes, quien afirma:

[...], todo en diverso grado significa algo en el relato. Esto no es una cuestión de arte, es una cuestión de estructura. El orden del discurso, todo lo que está anotado es por definición notable: aun cuando un detalle pareciera irreductiblemente insignificante, 
rebelde a toda función, no dejaría de tener al menos, en última instancia, el sentido mismo de lo absurdo o de lo inútil. Todo tiene un sentido o nada lo tiene. (1970, p. 16)

Es evidente que en la trama el juego con la palabra trasluce el tono burlesco con que se refleja la realidad que muestra al niño como creador de textos, capaz de integrar la ironía para permitir a sus lectores el disfrute con el lenguaje, contando mediante el uso coloquial un suceso que termina en tragedia: la muerte por asfixia de un cerdo que yacía enfermo desde la tarde anterior a su deceso, ironía que se hace notoria en el segundo párrafo del fragmento.

Cuando llegué a la casa, mi papá había vuelto, yo me puse muy contento, pero no dije nada, le ayudé a limpiar la marranera y nos dimos cuenta de que había un cerdo que estaba todo morado y parecía que se iba a infartar, mi papá y yo lo sacamos y lo metimos en otro corral que estaba desocupado, el marrano estaba mordido, tuvimos que cortarle una oreja, pero seguía morado casi muriéndose, entonces mi papá lo inyectó y comenzó a mejorar. Así pasó la tarde y la noche, el marrano como enfermo, pero parecía que estaba recuperándose.

Al día siguiente me fui a la escuela y el marrano estaba vivo y cuando volví por la tarde el marrano ya no estaba morado, estaba muerto. Le dije a mi papá que qué hacíamos con él y él dijo saquémoslo y arreglémoslo. Siempre los arreglábamos porque el patrón nos mandaba a eso y tocaba hacerlo porque era el trabajo de mis papás.

El escrito del estudiante Caleb participó en el mes de octubre de 2016 en la modalidad de cuento en un concurso de narrativas e imagen organizado por el colegio Colombia Hoy, ubicado en Facatativá por la vía Facatativá-Rosal, haciéndose acreedor del primer puesto por haber convertido en cuento su experiencia de vida. De este modo, Caleb adopta los conocimientos adquiridos a partir del proceso de intervención mediante la proposición de talleres de escrituras creativas encaminadas al reconocimiento de las experiencias vitales del estudiantado, independientemente del sector en que se produzcan (sea rural o urbano), atendiendo a que la educación es solo una y debe permear todos los espacios, posibilitando la recreación de la realidad, cualquiera que esta sea mediante la escritura creativa.

Así, el estudiante nos introduce en el entorno rural, a partir del título de su cuento, plasmando las condiciones de vida, los saberes previos y el capital cultural adquirido hasta entonces y resignificando a través de la escritura las labores en que involucran los niños del campo en sus tiempos de juego y aventura, convirtiendo a la escritura en espacio para narrar "la vida", desde la identidad que se refunde cuando pasamos de sujetos a objetos que se deben a las órdenes en ocasiones arbitrarias de un "patrón", quien dirige los destinos de una familia como el titiritero maniobra a su espantajo.

El mérito otorgado al niño escritor se instala en el vínculo que establece el lector con el trabajo infantil narrado en el texto, lo que permite que emerja el flujo de emociones en una sociedad que desconoce los trabajos y las fatiga a que se somete el niño en muchos lugares de la geografía nacional. Esto, a pesar de que desde las políticas públicas se determina que la población infantil debe asumir labores netamente escolares y la sociedad propender por su cuidado y por su defensa, cosa que en la práctica no sucede. Sin embargo, dichas políticas han instaurado un pensamiento proteccionista que va en contravía de las actividades extraescolares que son habituales como parte de la construcción de valores familiares en la población rural que asiste a la escuela, pero que producen afectaciones en el desempeño académico de los estudiantes. Véase en el texto de Caleb:

Yo llegué a la escuela muy cansado, no había dormido casi nada y en la escuela solo quería quedarme acostado en el pupitre, entonces la profesora de lenguaje me preguntó que qué era lo que me pasaba, yo le conté que había estado trabajando toda la noche debajo del aguacero organizando los marranos en las marraneras y que tenía mucho sueño, la profesora se puso triste y me abrazó.

En esta convocatoria el niño encontró en la acción de escribir la posibilidad de narrar su historia 
de vida a través de la palabra escrita, apartando-se de los usos instrumentales que se le ha dado a la enseñanza del lenguaje en la escuela y aprovechando la escritura como una oportunidad de reconocerse y reconocer al otro desde la singularidad.

La anterior experiencia contribuye a la afirmación de la hipótesis que se planteara al inicio de este artículo: solamente mediante la flexibilización en la enseñanza de la escritura se estimula la imaginación hacia un aprendizaje consciente del lenguaje capaz de insertar la realidad social, histórica y cultural de quien aprende a sus prácticas de escritura, afectando así las fibras más sensibles del grupo y facilitando una educación en y para la democracia, como réplica a la afirmación de qué:

Si el niño no llega a desarrollar algún sentido de lo que llamo "intervención reflexiva" sobre el conocimiento que encuentra, estará actuando continuamente de afuera hacia dentro - el conocimiento le guiará y le limitará-, pero si logra hacerlo, será él quien controle y seleccione el conocimiento que necesite. Si desarrolla un sentido del yo que esté basado en su capacidad para adentrarse en el campo del conocimiento para sus propios usos, y si puede compartir y negociar los resultados de esta acción, llegará entonces a ser un miembro de la comunidad creadora de cultura. (Bruner, 1998, p, 11)

\section{Discusión de resultados}

Durante el desarrollo de la investigación se estableció la ejecución de nueve talleres de escrituras creativas con un grupo de estudiantes de grado tercero de la sede rural Mancilla, ubicada en Facatativá. Dichos talleres fueron realizados en una dinámica de trabajo que atendía a la siguiente estructura: consigna-escritura-lectura de los textos producidos (o representación teatral)-evaluación grupal-producto. Los talleres se Ilevaron a cabo a partir de dos categorías teóricas que alentaron a los estudiantes a la creación de textos a partir de moldes retóricos en un juego intertextual con predominio de las funciones expresiva y poética; ello para promover en el grupo objetivo de la investigación la escritura de textos estéticos a partir de la experimentación y el juego con el lenguaje.
Es de anotar que las consignas utilizadas para facilitar en el grupo seleccionado la escritura de textos estéticos se encuentran acordes con la edad predominante de los estudiantes del grupo objetivo, sus intereses y los conocimientos que acerca de la escritura creativa de este tipo de productos tienen. Por tanto, los talleres de escritura propuestos agrupan una serie de ejercicios sencillos de producción escrita que mediante la escritura compartida e individual se posibilitaron.

Frente a la escritura de narrativas con la cual los estudiantes participaron en la convocatoria realizada por el colegio Colombia Hoy, se determinó que la enseñanza de la escritura creativa en la escuela sí contribuye al desarrollo de la sensibilidad literaria a partir de la creatividad. Esto lo devela la historia contada por el estudiante Caleb, quien mediante la escritura creativa narró su historia personal; un texto singular que refleja una escritura que se aparta del uso del manual dando paso a una que surge de las experiencias vividas del niño.

Ahora bien, a partir de la pregunta planteada al inicio del presente artículo, y de acuerdo con la lectura del contexto se reconoce que son escasas las posibilidades de escritura de invención que otorga la escuela a los estudiantes de básica primaria para conducirlos al dominio mínimo de la expresión escrita. Por el contrario, en la generalidad de los casos, en la escuela la escritura se constituye en un mecanismo para evaluar gramática y ortografía, mientras que la literatura se introduce como objeto de estudio de la lengua: Si bien estos aspectos son importantes y se apoyan en estudios, se expondrán más ampliamente en la propuesta de investigación titulada "La producción de textos estéticos en el aula de básica primaria; escritura creativa y subversión de la lengua materna".

\section{Conclusiones}

Para concluir, se resalta que, mediante la adopción de estrategias auténticas de recreación simbólica de la realidad subjetiva puestas en marcha a los estudiantes a través de talleres literarios mediados por consignas determinadas, se contribuye al desarrollo de habilidades que estimulan el uso metafórico del lenguaje, técnica que se convierte en entrenamiento para cualificar la escritura en 
los niños. Asimismo, los textos producto de dichas consignas se constituyen en un acercamiento a la producción estética, en la medida en que se derivan de la creatividad y se sustentan en el juego con la lengua-idioma mediante la liberación del significante y que se imbuye de magia para desbordar su sentido.

Por otra parte, la pertinencia de las intervenciones basadas en premisas de imaginación, creatividad y desarrollo de la sensibilidad humana y que propenden por la cualificación de procesos escriturales en los niños, se sustenta en que la escritura se convierte en una forma de imaginar otros modos de expresión, apartados de su uso instrumental, mediante la introducción de la lectura literaria que evidencia el uso de la metáfora para significar la realidad y abunda en figuras retóricas que aparte de dotar de gracia a un texto, aportan a la construcción de la subjetividad. De este modo, se supera el manido modelo tradicional de enseñanza de la lengua, involucrando la literatura como preámbulo para la generación de nuevas escrituras, ya que en la literatura se condensan todas las figuras que posibilitan el devenir de la imaginación. Por ello, se desarrolla en los estudiantes la capacidad de análisis alrededor de situaciones que se plantean en las consignas y para las cuales se requiere del ejemplo de cómo lo hicieron otros; ¡llámese a estos: quienes escriben!

También es interesante reconocer que en los talleres de escrituras creativas "la intromisión" de palabras creadas y recreadas por los estudiantes a una nueva producción escrita ayuda a comprender todas las dificultades de tránsito que supone el paso de la lengua oral a la lengua escrita que, a pesar de la proximidad del código, no basta con el traslado mecánico para lograr el efecto que cobran las palabras en la lengua oral informal. Se requiere de la adopción de fórmulas que apelan a los usos pertinentes de los signos de puntuación, signos de admiración, interrogaciones, uso de comillas, subrayados, letra en bastardilla y un sinnúmero de fórmulas que ayudan a representar en la escritura el estilo directo. Esta intrusión de palabras desarticuladas en estructuras sintácticas determinadas también incita a la reflexión acerca de la adquisición de la lengua, convirtiéndose en generadoras de preguntas sobre la pertinencia de la introducción de palabras inventadas en un texto organizado de manera lógica y sobre cómo hallar sentido a ese tipo de escrituras. Así las cosas, las respuestas conducen al aprendizaje de la lengua a partir del juego de recreación simbólica.

\section{Referencias}

Alonso, L. y Aguirre de R. (2004). La escritura creativa en la escuela: una experiencia pedagógica (de, con) juegos lingüísticos y metáforas. Revista de Pedagogía, 25(74):375-400. Recuperado de http://www.scielo.org.ve/scielo.php?script=sci_ arttext\&pid=S0798-97922004000300002\&ln$\mathrm{g}=\mathrm{es} \& \mathrm{nrm}=\mathrm{isO}>$

Alvarado, M. (1981). Teoría y práctica de un taller de escritura. Madrid: Altalena.

Álvarez, M. I. (2009). Escritura creativa. Aplicación de las técnicas de Gianni Rodari. Educere: Revista Venezolana de Educación, 13(44), 83-87. Recuperado de http://www.redalyc.org/articulo.oa?id=3561457101

Angulo, K. (2015). La biblioteca como espacio para la invención de relatos. Bogotá: Universidad Distrital Francisco José de Caldas.

Barthes, R. (2002). Variaciones sobre la escritura. Barcelona: Paidós.

Barthes, R., Greimas, A., Bremond, C., Gritti, J., Morin, V., Metz, C., Todorov, T. y Genette, G. (1970). Análisis estructural del relato. Buenos Aires: Tiempo Contemporáneo.

Bettelheim, B. (2001). Psicoanálisis de los cuentos de hadas. Barcelona: Crítica.

Bombini, G. (2006). Reinventar la enseñanza de la lengua y la literatura. Buenos Aires: Libros del Zorzal.

Bruner, J. (1998). Acción, pensamiento y lenguaje. Madrid: Alianza.

Contreras, C. y Giraldo, C. (2011). Escritura creativa. Un viaje entre lenguaje y pensamiento. En Giros de palabra. Lectura y escritura en BibloRed. Bogotá: Alcaldía Mayor de Bogotá.

Correa, C. (2015). El grafiti: un pretexto para cualificar la producción textual en la escuela. Bogotá: Universidad Distrital Francisco José de Caldas.

Coto, B. (2002). La escritura creativa en las aulas, entorno a talleres literarios. Barcelona: Graó. 
Eco, U. (1999). La estructura ausente. Introducción a la semiótica. Barcelona: Lumen.

Eliot, J. (1993). El cambio educativo desde la investigación acción. Madrid: Morata.

Fajardo, L. P. (2017). Ana Z y la literatura de fantasía en la infancia. Un acto de descubrimiento. Infancias Imágenes, 16(2), 326-329. Recuperado de https://revistas.udistrital.edu.co/ojs/index. php/infancias/article/view/11592/13337

Frugoni, S. (2002). Escribir ficciones: un camino hacia la literatura. Ponencia presentada en las Jornadas de Enseñanza de la Literatura del Instituto del Profesorado Alicia Moreau de Justo. Buenos Aires.

Frugoni, S. (2006). Imaginación y escritura. La enseñanza de la escritura en la escuela. Buenos Aires: Libros del Zorzal.

Held, J. (1981). Los niños y la literatura fantástica. Función y poder de lo imaginario. Barcelona: Paidós.

Jurado, F. (1992). La escritura: proceso semiótico reestructurador de la conciencia. Forma y Función, 6, 37-46.

Lakoff, G. y Johnson, M. (2009). Metáforas de la vida cotidiana. $8^{\mathrm{a}}$ ed. Madrid: Cátedra.
Ministerio de Educación Nacional de la República de Colombia (2008). Lineamientos Curriculares Lengua Castellana. Bogotá: Ministerio de Educación Nacional de la República de Colombia.

Ministerio de Educación Nacional de la República de Colombia (1998). Lineamientos Curriculares de Lengua Castellana. Bogotá: Cooperativa Editorial Magisterio.

Rodari, G. (1983). Gramática de la fantasía: introducción al arte de inventar historias. Barcelona: Argos Vergara.

Rodríguez, L. (2015). El relato de experiencia: una alternativa para fortalecer la producción escrita. Bogotá. Universidad Distrital Francisco José de Caldas.

Silva, J. (2015). El microcuento como estrategia para la enseñanza de la composición de textos con dominancia argumentativa. Bogotá: Universidad Distrital Francisco José de Caldas.

Tusón, A. (1991). Las marcas de la oralidad en la escritura. Signos: Teoría y Práctica de la Educación, 3, 14-19.

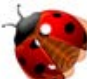

\section{(C) (1)(}

Esta obra está bajo licencia Creative Commons Atribución-NoComercial-Compartirlgual 4.0 Internacional https://creativecommons.org/licenses/by-nc-sa/4.0/deed.es ISSN 1657-9089 • Vol 18, No 1 (enero-junio 2019). pp. 80-94 